\title{
Synovial Sarcoma of the Left Palatine Tonsil Case Report and Review of Literature
}

\author{
Nasir A. Magboul (D) ${ }^{*}$, Mubarak AlQahtani², Abdulwahid S. ALQahtani ${ }^{3}$ and Taqwa Abdullah M Osman \\ ${ }^{1}$ Department of ORL-HNS, Armed Forces Hospital, Jizan. Saudi Arabia. \\ ${ }^{2}$ Department of ORL-HNS, Asser Central hospital, Saudi Arabia \\ ${ }^{3}$ Department of ORL-HNS, Armed Forces Hospital, Southern Region-Khamis Mushait, Saudi Arabia. \\ ${ }^{4} \mathrm{MD}$ pathology, Khartoum University, Sudan.
}

*Corresponding Author: Nasir A. Magboul, Department of ORL-HNS, Armed Forces Hospital, Jizan. Saudi Arabia.

Received date: September 13, 2021: Accepted date: October 25, 2021: Published date: November 04, 2021

Citation: Nasir A. Magboul, Mubarak A Qahtani, Abdulwahid S. ALQahtani ,Taqwa Abdullah M Osman (2021) Synovial Sarcoma of the left palatine tonsil case report and review of literature Journal of Clinical Otorhinolaryngology 3(4); DOI: 10.31579/2692-9562/039

Copyright: (C) 2021, Nasir A. Magboul. This is an open access article distributed under the Creative Commons Attribution License, which permits unrestricted use, distribution, and reproduction in any medium, provided the original work is properly cited

\begin{abstract}
Synovial sarcoma arises primarily in the lower extremities with a predilection for sites in proximity to large joints, such as the knee. It rarely occurs in the head and neck region, and the tonsil is an unusual site for the tumor, with only eight previously published cases in this anatomical site.

6-10\% of all soft tissue tumors, only 3-5\% arise in the head and neck region, and SS arising in the tonsil is a rare finding, with only eight well-documented cases reported in the English language literature. We describe the histopathological findings of a primary synovial sarcoma of the palatine tonsil arising in a 20 -year-old male, with presentation of dysphagia and sleep disturbance.
\end{abstract}

Keywords: synovial sarcoma, palatine tonsil, tonsillectomy, radiotherapy, chemotherapy

\section{Introduction}

Synovial sarcomas are rare soft tissue sarcoma that primarily arise from the extremities, especially the lower thigh-knee region [1].

It is a highly malignant soft tissue tumor, accounts for less than $1 \%$ of all head and neck malignant neoplasms [6].

The literature has shown that this tumor can be found in unusual sites such as the abdominal wall and the head and neck region which are non synovium-lined spaces [1].

Although the head and neck are rare primary site for synovial sarcoma, only $3-5 \%$ of these neoplasms appear in this region [2]. The parapharyngeal space is the most common location for synovial sarcoma $[3,4]$ Primary synovial sarcoma of the palatine tonsil is extremely rare [5].

A high clinical suspicion, careful examination, proper imaging and histopathological exam needed to diagnose those kind of condition.

This article is about a rare case of synovial sarcoma which originated in the left palatine tonsil.

\section{Case report}

A 20-year-old male patient presented to our otolaryngology clinic with history of difficulty in swallowing, disturbance of sleep and fullness in the throat since more than 2 months.

On and off difficulty in breathing specially during supine position. He did not have other symptoms relating to the ear, nose and throat. He had no history of a loss of weight or appetite. Patient not known to have any medical or surgical issue before, and he is not smoker.

Patient was fully conscious oriented and vitally stable. Oral examination showed left pedunculated purple mucosal arising from right tonsil mass projected just behind the anterior pillar crossing the midline and reaching up to the right tonsil No cervical lymphadenopathy was noted.

Findings on the remainder of the ENT examination were normal.

Revealed the presence of a pedunculated mucosal lesion projecting into oropharynx arising from just be- hind the posterior pillar of tonsil on left side. No cervical lymphadenopathy was noted. Findings on the remainder of the ENT examination were normal.

CT scan of the head and neck area done and showed large ill-defined 
heterogenous enhancing noncalcified soft tissue lesion measured about $4.5 * 41 * 40 \mathrm{~mm}$ obliterating the oropharyngeal space compressing the left side of nasopharynx, with sub centimetric cervical lymph node.

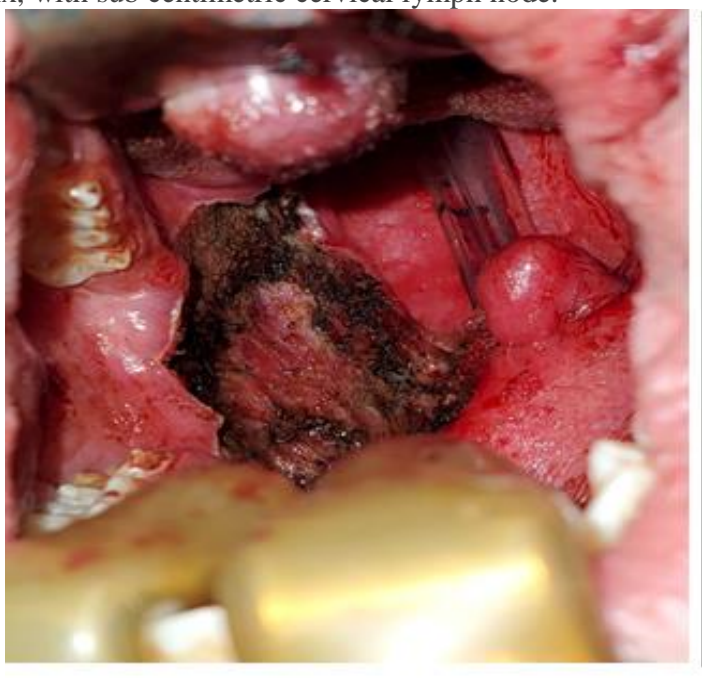

The patient underwent excisional biopsy of the mass and the left palatine tonsil and send it to the histopathology.

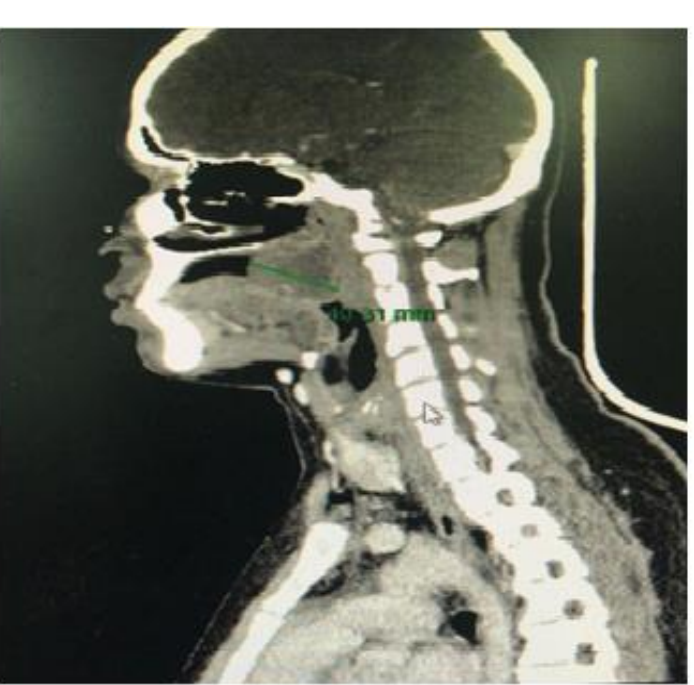

\section{Figure 1}
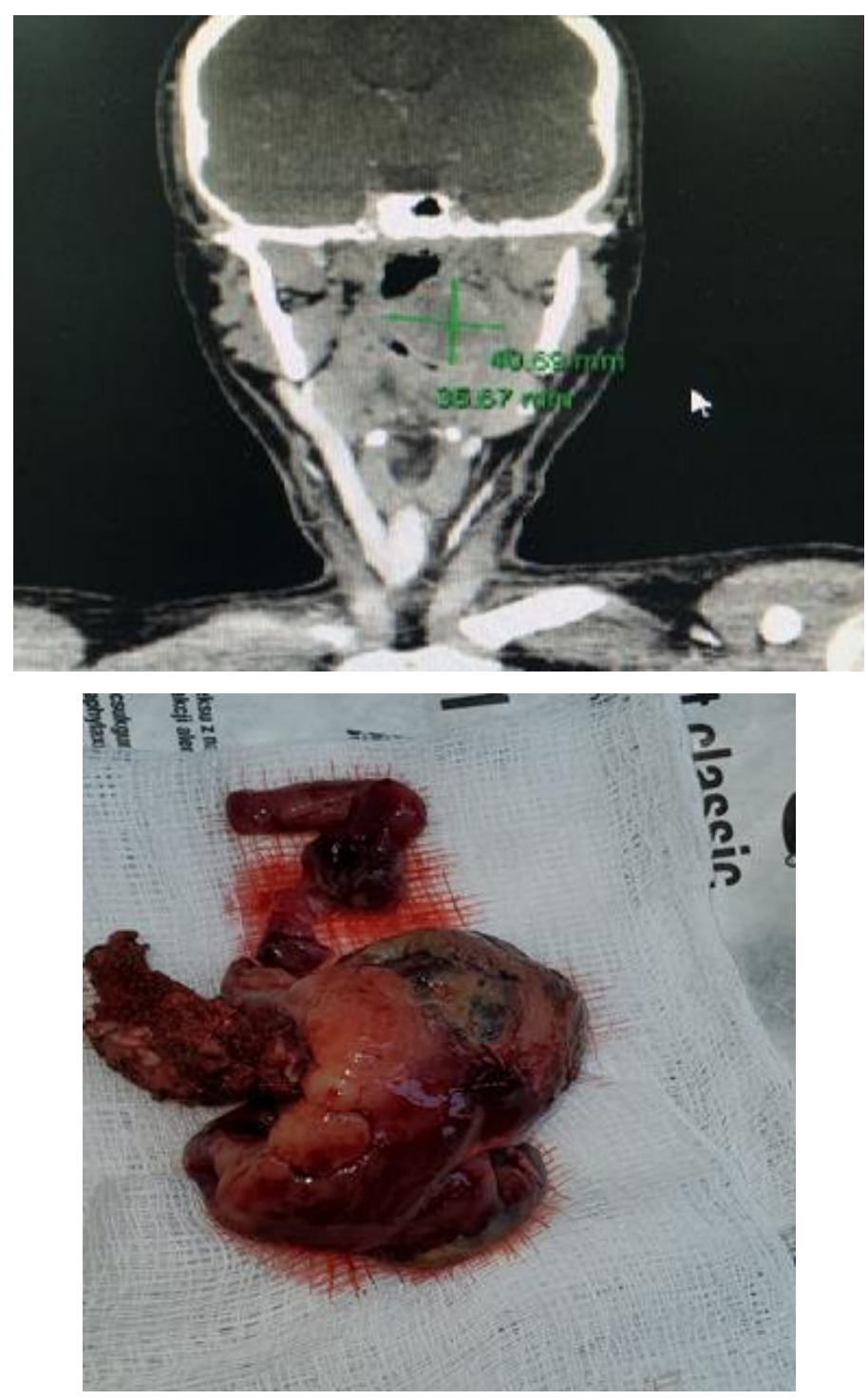


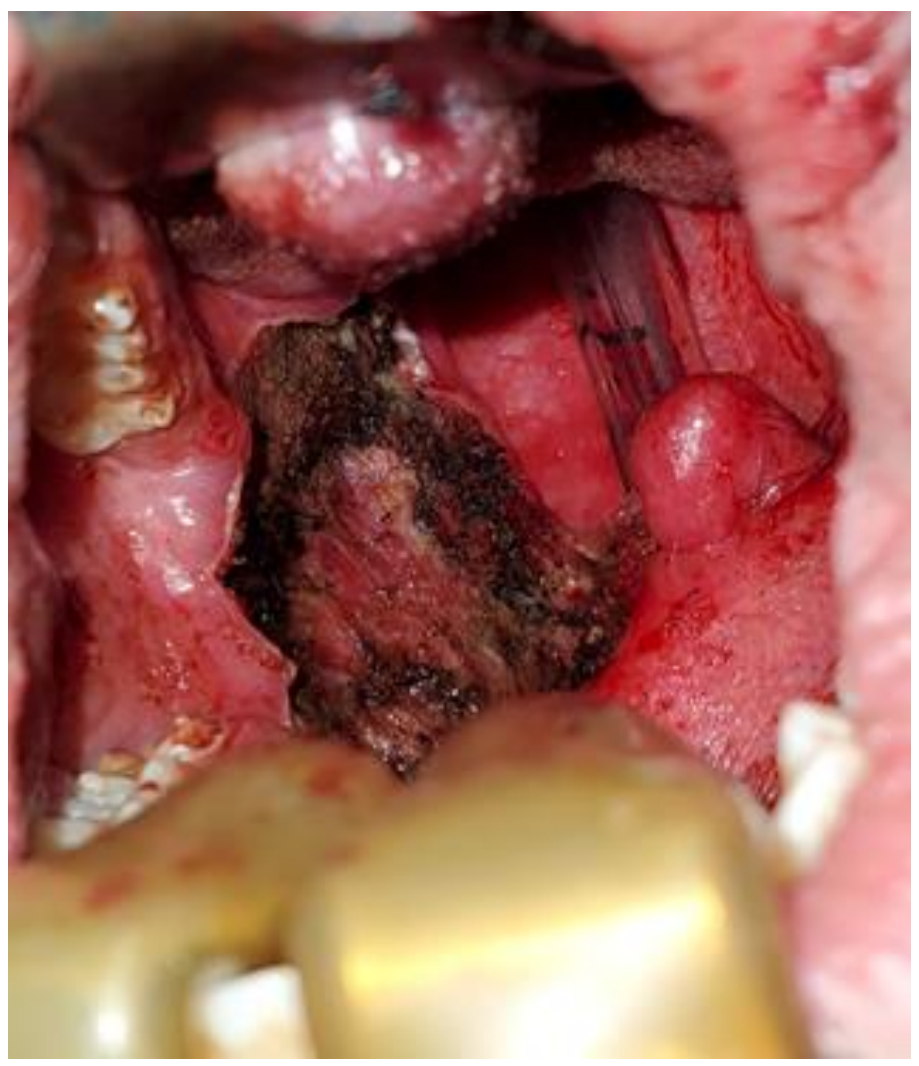

Histopathologic examination showed biphasic tumor with slit like spaces lined by epithelial cells and Spindle cells.

Immunohistochemistry highlighted spindle cells strongly expresses for vimentin, focal weak cytoplasmic positive for bcl-2, pan cytokeratin positive in epithelial cells and CD99 was negative consistent with Synovial sarcoma Carcino sarcoma.

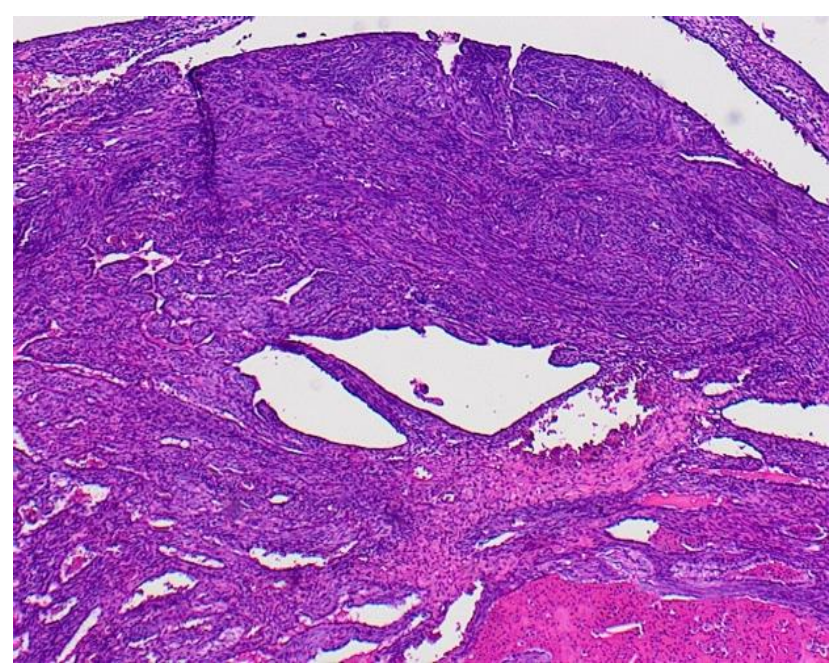

Biphasic tumor
Patient then referred to higher center and received adjuvant radiotherapy. Case was followed up for 1 years for both local and metastatic work up and is free of any symptoms.

We lost the connection with the patient since then.

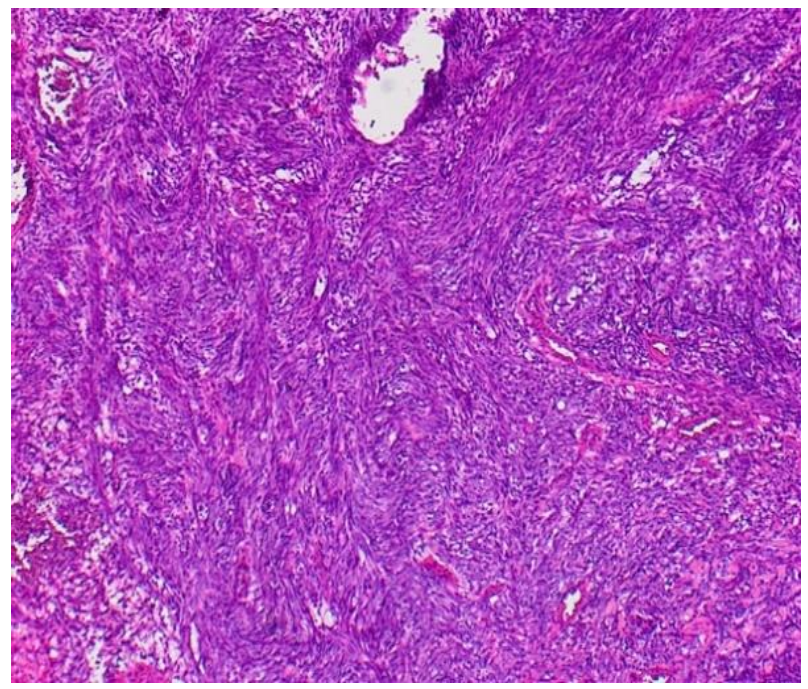

Spindle cell component $\mathbf{x} 10$ 


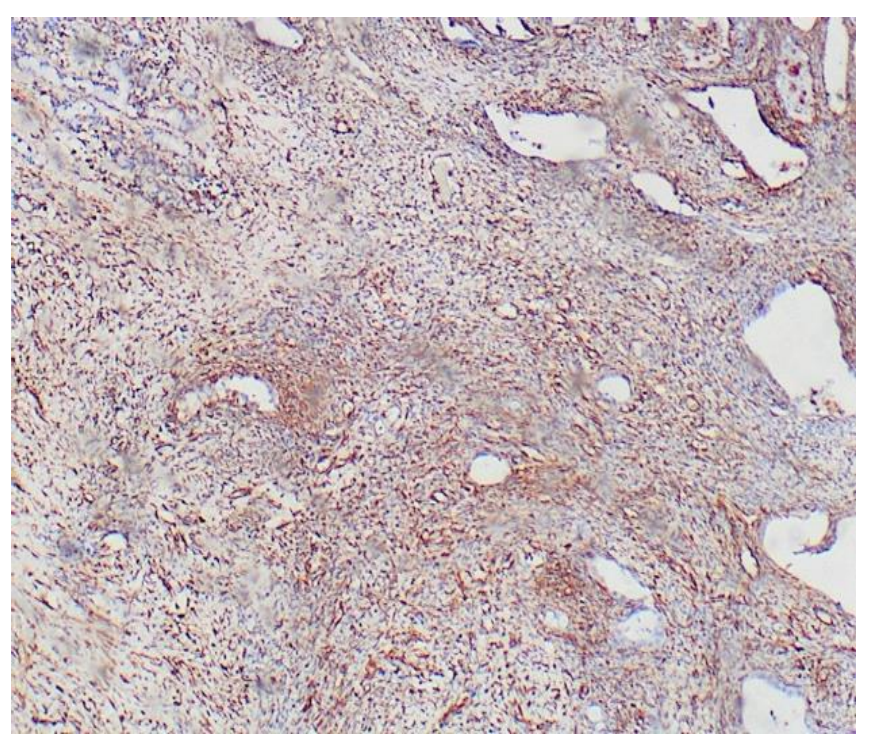

Vimentin positive in spindle cells

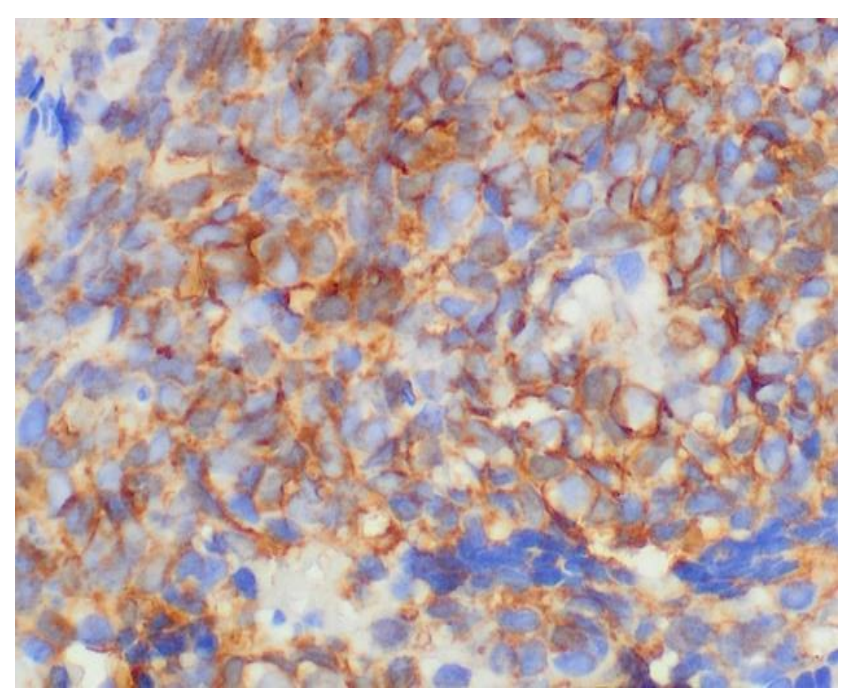

CD99: Focally positive

\section{Discussion}

Among the rare and aggressive malignant neoplasms that occur in the head and neck, the soft tissue sarcomas represent about $1 \%$ of all head and neck cancers, and about $4 \%$ to $10 \%$ of all soft tissue sarcomas in adults. Head and neck site sarcomas occur more frequently in the scalp, the face, and the neck area [6]. Sarcomas of the head and neck tend to recur locally more frequently and have a worse outcome than tumors elsewhere in the body [7].

Synovial sarcoma, a highly malignant soft tissue tumor, accounts for less than $1 \%$ of all head and neck malignant neoplasms, according to the site of involvement those kind of malignant neoplasm may present with diffident clinical presentation, in tonsillar area the presentation ranging from mild dysphagia to sleep disturbance, or even more severe airway compression [6].

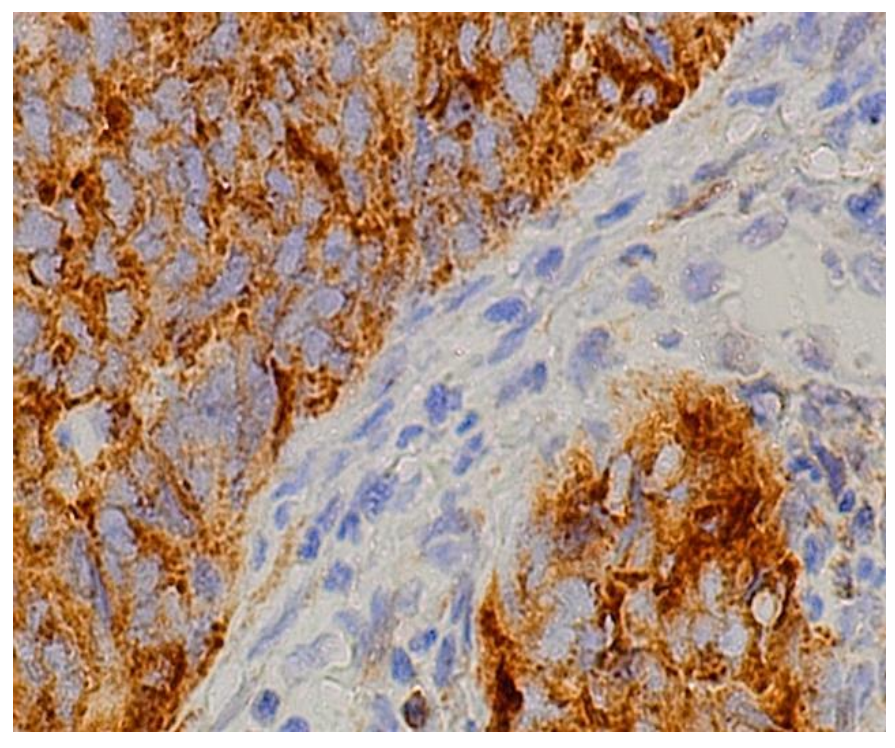

\section{bcl-2: Focal positive}

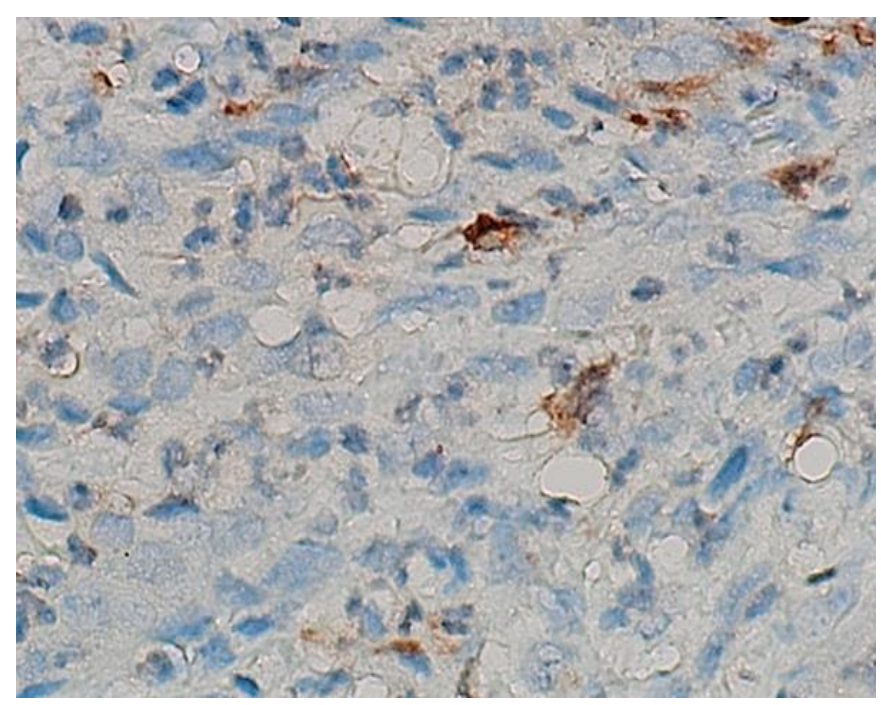

\section{S100: focally positive}

In the head and neck region, synovial sarcoma most commonly affects the parapharyngeal space. To date, there have been approximately 100 cases of synovial sarcoma of the head and neck region reported in the literature [8].

Prior to treatment clinical and imaging examinations should be considered for all patients with head and neck synovial sarcoma.

The clinical findings of those cases advocate that the extent of the resection have to be decided through preoperative imaging studies, especially CT and MRI, with the cause to pick out top-quality surgical techniques and avoid suboptimal surgical resection. further, a preoperative incisional biopsy for destiny direct surgical planning is tremendously endorsed [9]. Histologically, synovial sarcoma presents as monophasic, biphasic, or uncommonly poorly differentiated subtypes.[9] Synovial sarcoma may cause differential diagnostic challenges with other 
soft tissue sarcoma, such as fibrosarcoma, leomyosarcoma and clear cell sarcoma.

Special immunohistochemical stains are helpful for differentiating synovial sarcoma from other soft tissue sarcomas. However, the precise diagnosis of synovial sarcoma can be difficult with histopathological and immunohistochemical studies alone.

Detection of this specific chromosomal translocation is helpful in confirming the diagnosis of synovial sarcoma, particularly when histological studies are uncertain [9].

Therefore, if the results of histopathological and immunohistochemical studies are inconclusive and there is a high clinical suspicion of synovial sarcoma, molecular genetic testing should be considered for diagnostic confirmation. [9].

According to the general principles of high-grade soft tissue sarcoma, standard local therapy for synovial sarcoma consists of wide surgical resection and adjuvant radiotherapy when appropriate [10].

Synovial sarcoma is one of the most chemo sensitive soft tissue sarcomas, with about $50 \%$ response rates to ifosfamide - and doxorubicinbased regimens. In an effort to improve systemic disease control and survival, adjuvant chemotherapy is widely used [10].

Currently, ifosfamide-based regimens with or without doxorubicin are considered the first choice of chemotherapy for patients with locally advanced and metastatic synovial sarcoma. [10-11].

\section{Conclusion}

The diagnosis of synovial sarcoma in head and neck is rare and should be kept in mind as one of differential diagnosis even in such unusual sites as the tonsils, especially when patient presented with rapid progression of unilateral tonsillar mass causing dysphagia and compromising the airway.

\section{Funding}

This research received no specific grant from any funding agency in thepublic, commercial, or not-for-profit sectors.

\section{Declarations of interest}

The Authors declare that there is no conflict of interest.

\section{References}

1- Hale JE, (1970) Calder IM. Synovial sarcoma of the abdominal wall. Br J Cancer;24(3):471-4. doi: 10.1038/bjc.1970.56. PMID: 4319939; PMCID: PMC2008600.

2- Eilber FC, (2008) Dry SM. Diagnosis and management of synovial sarcoma. J Surg Oncol. Mar 15;97(4):314-20. doi: 10.1002/jso.20974. PMID: 18286474.

3- Khademi B, (2006) Mohammadianpanah M, Ashraf MJ, Yeganeh F. Synovial sarcoma of the parapharyngeal space. Auris Nasus Larynx. (2007) Mar;34(1):125-9. doi: 10.1016/j.anl. Epub. PMID: 17056221.

4- Boniver V, (2005) Moreau P, Lefebvre P. Synovial sarcoma of the larynx: case report and literature review. B-ENT;1(1):47-51. PMID: 15999676.

5- Ishiki H, Miyajima C, Nakao K, Asakage T, Sugasawa M, Motoi T. (2009) Synovial sarcoma of the head and neck: Rare case of cervical metastasis. Head Neck;31:131-5.

6- Mendenhall WM, Mendenhall CM, Werning JW, Riggs CE, Mendenhall NP. (2005) Adult head and neck soft tissue sarcomas. Head Neck;27(10):916-22. doi: 10.1002/hed.20249. PMID: 16136585.

7- Kraus DH, Dubner S, Harrison LB, Strong EW, Hajdu SI, Kher U, Begg C, Brennan MF. (1994) Prognostic factors for recurrence and survival in head and neck soft tissue sarcomas. Cancer. 15;74(2):697-702. doi: 10.1002/10970142(19940715)74:2<697::aid-cncr2820740224>3.0.co;2-a. PMID: 8033050.

8- Sturgis EM, Potter BO. Sarcomas of the head and neck region. Curr Opin Oncol 15:239-52.

9- Kottu R, Prayaga AK. (2003); Synovial sarcoma with relevant immunocytochemistry and special emphasis on the monophasic fibrous variant. $J$ Cytol;27(2):47-50. doi: 10.4103/09709371.70736. PMID: 21157548; PMCID: PMC3001174.

10- Eilber FC, Dry SM. (2008) Diagnosis and management of synovial sarcoma. J Surg Oncol.;97(4):314-20. doi: 10.1002/jso.20974. PMID: 18286474.

11- Park K, van Rijn R, McHugh K. (2008) The role of radiology in paediatric soft tissue sarcomas. Cancer Imaging.;8(1):102-115. Published 2008 Apr 22. doi:10.1102/1470-7330.2008.0014

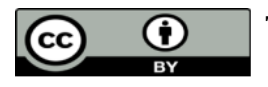

This work is licensed under Creative Commons Attribution 4.0 License

To Submit Your Article Click Here: Submit Manuscript

DOI: $10.31579 / 2692-9562 / 027$
Ready to submit your research? Choose Auctores and benefit from:

$>$ fast, convenient online submission

$>$ rigorous peer review by experienced research in your field

$>$ rapid publication on acceptance

$>$ authors retain copyrights

$>$ unique DOI for all articles

$>$ immediate, unrestricted online access

At Auctores, research is always in progress.

Learn more auctoresonline.org/journals/journal-of-clinicalotorhinolaryngology 